\title{
PROPOSTA DE IMPLEMENTAÇÃO DE ESTRATÉGIAS DE MONITORAMENTO E CONTROLE PARA REDUÇÃO DE PERDAS DOS INSUMOS NAS INSTALAÇÕES DE SERVIÇOS: ESTUDO DE CASO NA EMPRESA INFORTREAD
}

\section{ARTIGO ORIGINAL}

GONÇALVES, Mayara Moraes ${ }^{1}$ BRITO, William de Souza², SOUZA, Thalisson Figueiredo ${ }^{3}$, DUTRA, Paulo José Franco ${ }^{4}$, OLIVEIRA, Daniel Barroso de ${ }^{5}$, ALMEIDA, Victor da Silva ${ }^{6}$, ROBERTO, José Carlos Alves ${ }^{7}$

GONÇALVES, Mayara Moraes. Et al. Proposta de implementação de estratégias de monitoramento e controle para redução de perdas dos insumos nas instalações de serviços: estudo de caso na empresa Infortread. Revista Científica Multidisciplinar Núcleo do Conhecimento. Ano. 06, Ed. 11, Vol. 15, pp. 116-138. Novembro de 2021. ISSN: 2448-0959, Link de acesso: https://www.nucleodoconhecimento.com.br/administracao/estrategias-demonitoramento, DOI: 10.32749/nucleodoconhecimento.com.br/administracao/estrategias-demonitoramento

\section{RESUMO}

O presente artigo tem a finalidade de estudar alternativas operacionais para a empresa INFORTREAD, localizada em Manaus. Observou-se no diagnóstico

\footnotetext{
${ }^{1}$ Graduando do curso de Administração.

${ }^{2}$ Graduando do curso de Administração.

${ }^{3}$ Graduando do curso de Administração.

${ }^{4}$ Graduando do curso de Administração.

${ }^{5}$ Coorientador. Bacharel curso de Administração.

${ }^{6}$ Coorientador. Mestre em Engenharia de Processos. Pós-Graduando em Neuropsicopedagogia Institucional. Especialista em Gestão Estratégica de RH. Graduado em Administração e Pedagogia.

${ }^{7}$ Orientador. Mestrado profissional em Engenharia de produção. Especialização em Gestão em Logística empresarial. Graduação em Administração com Ênfase em Marketing.
}

RC: 102385

Link de acesso:

https://www.nucleodoconhecimento.com.br/administracao/estrategias-de- 
organizacional que a empresa é reconhecida pela qualidade dos serviços prestados na região, porém, detectou-se que a organização necessitava rever seus processos, visando manter a qualidade e controlar os custos dos serviços realizados. Sendo assim, o presente estudo de caso tem como pergunta-problema: Como reduzir as perdas dos insumos nas instalações por meio da implementação e controle dos serviços? Como objetivo geral do estudo, apresenta-se uma proposta com estratégias voltadas à redução de perdas dos insumos nas instalações em relação aos serviços prestados, pois observou-se, na empresa, a falta de controle dos insumos utilizados. Os aspectos metodológicos deste artigo se caracterizam como pesquisa aplicada; exploratória, explicativa e intervencionista; sendo realizada uma pesquisa de campo. Busca-se, portanto, estruturar um mapeamento completo do processo, criar mapas inteligentes para a gerência e supervisionar as operações diárias, com ênfase na implantação do ciclo PDCA para melhoria contínua e da Curva $A B C$ para reduzir a aquisição de insumos desnecessários. Pretende-se, também, elaborar um treinamento de redução de custos voltado para os técnicos de instalações e, assim, criar um formulário de controle para obter as informações dos insumos utilizados nas realizações dos serviços. Os resultados observados foram satisfatórios, a ferramenta da qualidade $5 \mathrm{~W} 2 \mathrm{H}$ foi utilizada como instrumento de organização da proposta inerentes às implementações necessárias à melhoria no setor indicado. Com isso, entende-se que os propósitos do artigo foram atendidos no sentido de que as ações propostas prepararam a empresa para solucionar os problemas relativos ao controle de custos e acompanhamento das ações, com o intuito de que houvesse melhorias na área de logística, sobretudo no controle de insumos e redução de perdas, evitando custos maiores para a organização, bem como os colaboradores tornaram-se mais conscientes quanto às responsabilidades de execução, obtendo-se uma melhoria na otimização do desempenho com o mapeamento dos processos e controle de estoque e seus materiais, isto sem perder a qualidade reconhecida no mercado por seus serviços prestados.

Palavras-Chaves: Logística, Ferramentas, Mapeamento de Processo, Controle de estoque e insumo, Redução de Custo, Perdas.

RC: 102385

Link de acesso:

https://www.nucleodoconhecimento.com.br/administracao/estrategias-de- 


\section{INTRODUÇÃO}

Este artigo trata-se de um estudo de caso realizado na empresa INFORTREAD. A sua atividade principal é o fornecimento de internet para todo Estado do Amazonas, mas também contribui com outras atividades, como, por exemplo, com o desenvolvimento de sistemas para diferentes fins e com o seu devido suporte. É considerada como uma empresa de pequeno porte. $O$ estudo de caso realizado pela equipe contou com o manuseio de ferramentas que foram utilizadas para 0 diagnóstico, de modo que foi encontrada a área mais crítica da empresa, sendo ela a área da logística, pois apresentou diversos problemas que precisavam ser resolvidos. Assim, temos como proposta, com este artigo, estruturar os procedimentos relativos ao controle de materiais utilizados nos serviços prestados na empresa. Toda pesquisa parte de um problema. O problema de pesquisa implica a promoção do direcionamento que a pesquisa terá que seguir. É uma oportunidade para o pesquisador explorar, buscar compreender e até mesmo comprovar ou solucionar o tema proposto ao qual se deseja investigar.

O problema de pesquisa é apresentado de várias formas. Uma delas surge na forma de pergunta (LIBÓRIO; TERRA, 2015). Este artigo pretende responder ao seguinte problema de pesquisa: Como reduzir as perdas dos insumos nas instalações por meio de implementação e controle dos serviços? As metodologias utilizadas neste artigo, quanto à natureza, caracterizam-se como aplicadas, visto que a pesquisa promove a discussão a partir de um estudo de caso; quanto aos fins, trata-se de uma pesquisa exploratória, explicativa e intervencionista; quanto aos meios, tem-se como referência o estudo de caso e um estudo bibliográfico. As ações que serão feitas para alcançar o objetivo geral deste estudo serão divididas por partes para, consequentemente, alcançarem o resultado esperado, de modo que, em um primeiro momento, serão utilizados conceitos bibliográficos que, por sua vez, apresentarão suas metodologias científicas essenciais.

RC: 102385

Link de acesso:

https://www.nucleodoconhecimento.com.br/administracao/estrategias-de- 
Também será enfatizado, de forma empírica, como tudo irá acontecer, envolvendose, nesse processo, todas as ferramentas necessárias, como, por exemplo, a ferramenta $5 \mathrm{~W} 2 \mathrm{H}$, com o intuito de alcançar o objetivo geral, que é a busca por melhorias aplicadas à área da Logística. Com todos os objetos de estudo envolvidos no estudo de caso na pesquisa bibliográfica correspondente, foram traçadas estratégias essenciais à concretização, na prática, dos conceitos advindos dos embasamentos, isto é, das teorias científicas e demais ferramentas que permitiram solucionar os problemas identificados no diagnóstico da empresa INFORTREAD. Espera-se apresentar a empresa a partir de um conjunto de ações interventivas, estratégias que possibilitem que possa solucionar os problemas identificados no diagnóstico realizado na organização estudada, sendo essa a contribuição social do estudo.

\section{FUNDAMENTAÇÃO TEÓRICA}

O objetivo principal da fundamentação teórica é correlacionar tudo o que foi extraído do conhecimento científico relevante, apresentando, portanto, um novo contexto associado ao assunto, uma nova visão, processo esses necessários ao debate aprofundado do tema. É um processo que busca apontar os problemas, a delimitação de tema, os objetivos propostos, justificativas, trazer algo produtivo à investigação. Ela reúne todos esses processos para fornecer embasamento teórico ao estudo (RAUEN, 2018).

\subsection{MAPEAMENTO DE UM PROCESSO}

A gestão de processos atuais, principalmente as voltadas ao mapeamento, tem os resultados obtidos por meio das técnicas de gestão, sendo elas muito importantes para a organização. Para Muller (2014), a gestão de processos refere-se à principal ferramenta para entender os processos, que é o mapeamento a partir de uma representação visual das atividades e funções diversas da organização, identificando oportunidades de simplificação. A parte dos insumos refere-se a vários

RC: 102385

Link de acesso:

https://www.nucleodoconhecimento.com.br/administracao/estrategias-de- 
formatos de desenvolvimentos de atividades, sejam eles de forma individual ou em conjunto, obtendo-se variações relacionadas à empresa. O processo, então, fomenta a contínua transformação dos seus produtos ou serviços, assim como modifica a forma de fidelidade e compromisso com seu cliente, atentando-se ao processo de pedido e ao controle de estoque.

O gerenciamento dessas tecnologias tem se expandido rapidamente no setor de logística em diversos países. As cadeias de fornecimento têm sido aperfeiçoadas em todas as aplicações dos fundamentos da Indústria 4.0 (MOTTA, 2018). O estoque tem suas finalidades voltadas ao mapeamento de quaisquer quantidades de bens físicos, de produtos de insumos e de materiais que precisam ser armazenados em determinado tempo dentro de uma organização.

\subsubsection{IMPORTÂNCIA DO GERENCIAMENTO DE OPERAÇÕES}

Com o aumento da competitividade no cenário empresarial, os consumidores têm sido cada vez mais rigorosos quanto ao que consomem. A gestão de operações tem se mostrado essencial ao sucesso da organização. Uma das vantagens é o fato de permitir uma relação ampliada entre as demandas do cenário empresarial e a proposição de soluções que visam otimizar os resultados da organização. Ao longo do tempo foram surgindo diversas formas de gerenciar, cada uma delas dedicadas às necessidades da empresa, tendo como objetivo fazer com que a estratégia do mercado adotada funcione (BIAGIO, 2015).

A realização de um bom gerenciamento das operações é de vital importância ao processo de controle dos custos, obtendo-se redução dos custos, o que permite, à organização, ter vantagens e benefícios (SILVA, 2015). Quando o gerenciamento das operações não é praticado, a organização pode correr o risco de ter grandes problemas operacionais em uma determinada área, o que pode afetar a cadeia produtiva e comprometer os objetivos finais. $\mathrm{O}$ gerenciamento permite alinhar todos

RC: 102385

Link de acesso:

https://www.nucleodoconhecimento.com.br/administracao/estrategias-demonitoramento 
os processos para restaurar o equilíbrio interno da organização e garantir a adesão a uma rotina ao executar as atividades corretas.

\subsubsection{CICLO PDCA}

Segundo Marshall Junior (2012), o ciclo PDCA é a análise de todo processo ou objeto investigado que demanda um melhoramento contínuo. O Ciclo PDCA foi idealizado por Shewhart, mas foi Deming, o responsável pela implantação, que desenvolveu e fez o reconhecimento desse ciclo. Para obter uma melhoria contínua e sistemática dentro de uma organização ou objeto a ser estudado, o ciclo PDCA deve ser praticado de forma cíclica e sem interrupção do processo. As quatro fases são definidas e explicadas a seguir: Plan (planejamento): definir as metas e os métodos; Do (Execução): educar e treinar, executar a tarefa e coletar dados; Check (verificação): verificar os resultados da tarefa executada; e Act (agir corretivamente): agir corretivamente ou padronizar. Podemos explicá-las de forma sequencial, pois é dessa forma que são definidas:

A primeira fase, como indicado, é o Plan (planejamento) - Devem ser desenvolvidos os procedimentos com métodos e padrões para que sejam estabelecidas metas e objetivos, com o intuito de alcançá-los. A segunda fase é o Do (execução) - Nessa fase, é preciso ter a capacidade de educar e treinar para a execução para que sejam desenvolvidos os métodos na fase de planejamento. É a designada fase de implementação do planejamento. A terceira fase é a Check (verificação) - É quando se compara as metas desejadas com os resultados obtidos e é verificado se o que foi planejado foi consistentemente alcançado. São utilizadas, normalmente, ferramentas de controle e acompanhamento, como histogramas, cartas de controle, folhas de verificação, dentre outros. A quarta fase é a Act (agir corretivamente).

Há duas alternativas nesta fase. A primeira é a busca pelas causas fundamentais que permitem evitar riscos, isto é, a repetição dos efeitos indesejados, ou seja, emprega-se métodos para que as metas planejadas sejam alcançadas. A segunda

RC: 102385

Link de acesso:

https://www.nucleodoconhecimento.com.br/administracao/estrategias-demonitoramento 
diz respeito à adesão ao padrão que foi planejado da primeira fase, caso as metas que foram planejadas tenham sido alcançadas. Quando o ciclo PDCA funciona, este aumenta a previsibilidade em processos e aumenta até mesmo a competitividade organizacional. Essa previsibilidade acontece quando se segue todos os padrões indicados, pois detecta-se uma melhoria, o que torna o negócio bem-sucedido. Assim sendo, pode-se adotar o método planejado de forma padronizada, pois, caso não haja padronização no método planejado, volta-se ao padrão anterior e recomeça-se a girar o PDCA novamente. Esses são termos que apontam para a melhoria contínua na área que almeja qualidade (MARSHALL JUNIOR, 2012).

Além da aplicação da ferramenta do PDCA, há várias outras ferramentas que dão suporte ao processo, como a matriz GUT, pois esta auxiliará na etapa de planejamento do ciclo do PDCA, permitindo, portanto, a identificação das causas para a elaboração do plano de ação (BOND; BUSSE; PUSTILNICK, 2012).

\subsubsection{CLASSIFICAÇÕES DA CURVA ABC}

É a ferramenta mais utilizada na gestão de estoque. A partir da Curva $A B C$, os produtos são classificados em $A, B$ ou $C$ e são divididos conforme a utilização de consumo na organização. Os itens de nível $A$ são tratados com uma das maiores prioridades. Em seguida, os itens $B$ e $C$, respectivamente. Segundo Fernandes (2017), a Curva $A B C$, ou classificação $A B C$, é resultado da análise de Pareto. $A$ análise de Pareto é útil para melhorar a relação custo-benefício ou a razão custo e benefício em um sistema de estoque. Os itens que chegam em $20 \%$ correspondem a $75 \%$ do valor em estoque, sendo classificados como classe A.

Os itens $30 \%$ correspondem a $15 \%$ do valor em estoque e são classificados como classe B. Os itens $50 \%$ correspondem a $10 \%$ do valor em estoque e são classificados como classe $\mathrm{C}$. Existe a necessidade de utilizar as ferramentas que auxiliam nos gerenciamentos de estoque da organização, com objetivo de obter maior eficiência nos processos e alcançar melhorias para área, visando os ganhos.

RC: 102385

Link de acesso:

https://www.nucleodoconhecimento.com.br/administracao/estrategias-demonitoramento 
As organizações são capazes de criar planos estratégicos para melhorias do fluxo de entrada e saída de materiais, evitando, com isso, desperdícios de recursos, favorecendo a lucratividade da organização (GIMENES, 2018).

\subsubsection{TREINAMENTO E DESENVOLVIMENTO DE PROCESSOS}

Segundo Suzano (2013), na gestão organizacional, Recursos Humanos é o conjunto dos empregados ou dos colaboradores dessa organização. É uma função que visa, adquirir, desenvolver, usar e reter os colaboradores da organização. Busca-se alcançar o nível de desempenho desejado pela organização por meio do desenvolvimento constante das pessoas nas organizações. É importante constituir e desenvolver uma cultura essencial favorável ao aprendizado e empenhada com as alterações da organização. O relevante é compreender que, independentemente do foco utilizado pela organização, o treinamento e o desenvolvimento serão indispensáveis para a busca da perfeição nos negócios.

Os processos organizacionais, por sua vez, são atividades coordenadas que envolvem pessoas, procedimentos, recursos, informações e tecnologias. Para eficiência do processo de treinamento, para que as evoluções sejam nítidas, deve-se reforçar a indispensabilidade do treinamento. Os processos sempre estarão diretamente ligados às pessoas ( FERREIRA, 2014).

\subsubsection{ORGANIZAÇÃO E CONTROLE DE ESTOQUE}

O estoque e o armazenamento de materiais são necessários para que o negócio possa suprir as necessidades de produção e venda dos seus produtos. A depender do tipo da empresa, podem ser organizados de várias maneiras diferentes. Dentre os elementos que os compõem, menciona-se a matéria-prima, produtos não acabados e produtos acabados. Uma das questões que influencia a programação e organização de estoque é o balanceamento das diferentes demandas de estocagem. Por exemplo: a organização financeira visa que não haja diferenças que possam comprometer sua produção, as despesas excessivas, o fluxo de caixa, bem

RC: 102385

Link de acesso:

https://www.nucleodoconhecimento.com.br/administracao/estrategias-de- 
como o setor comercial, que necessita de uma reserva maior de produtos acabados, evitando que os clientes sofram com demoras ou falta de mercadoria, o que pode impactar no negócio.

A organização, para que possa ter um melhor controle do estoque, precisa partir de um processo planejado, regulamentado, sistematizado e coordenado, voltado à entrada e saída dos insumos para evitar problemas operacionais (FERNANDES, 2012). A gestão de estoque está relacionada aos processos de tomada de decisões sobre os materiais que farão parte do estoque da empresa, com ênfase nas suas quantidades. Existe outro fator que influencia o processo de estocagem e o espaço necessário para o armazenamento dos materiais da organização, pois, sem espaço, não seria possível armazenar os produtos de maneira correta (BRITO JUNIOR; SPEJORIM, 2012). O controle de estoque é responsável pelos processos de registro, fiscalização e gestão de entradas e saídas de mercadorias e produtos que são adotadas pela organização.

Concentra-se tanto no controle tanto da matéria-prima quanto das mercadorias produzidas ou vendidas e das ferramentas e equipamentos disponíveis. Os principais tipos de estoque dentro de uma empresa são:

- Matéria-prima: são itens comprados e recebidos que ainda não entraram no processo de produção;

- Produtos em processo: matérias-primas que já entraram no processo de produção e estão em operação;

- Produtos acabados: são produtos que saíram do processo de produção e aguardam para serem vendidos como itens completos.

As organizações devem dispensar a devida atenção quanto aos cuidados necessários aos tipos de estoque que desejam incorporar no dia a dia, sendo eles essenciais para o funcionamento de qualquer organização. Busca-se minimizar os investimentos dentro do estoque, tendo em vista suas necessidades, pois ele possibilita que as demandas sejam atingidas de forma satisfatória. O controle de

RC: 102385

Link de acesso:

https://www.nucleodoconhecimento.com.br/administracao/estrategias-de- 
estoque tem função de controlar ou de melhorar o seu material para atender às necessidades das organizações.

\section{MATERIAIS E MÉTODOS}

A metodologia é a área que estuda os métodos utilizados para identificar determinados conhecimentos. Os envolvidos utilizam-se de características que permitem executar cada ação voltada à determinação e direcionamento do estudo, partindo-se de questões que permitem chegar aos resultados (MIGUEL, 2012).

A metodologia de pesquisa discorre sobre como será executada a pesquisa e sobre o modelo metodológico a ser adotado. Elaborou-se o procedimento do trabalho a partir de métodos que permitiram identificar a proposta mais adequada a ser aplicada, de acordo com as necessidades da empresa delimitada, a INFORTREAD (GOBBI, 2012).

A pesquisa partiu de métodos que permitiram colocar em prática os procedimentos necessários à chegada às soluções mais adequadas para atender às necessidades da organização.

\subsection{PROCEDIMENTOS METODOLÓGICOS}

Os procedimentos metodológicos permitem a escolha do método, bem como do instrumento a ser utilizado. Este trabalho foi elaborado por meio da coleta de informações e dados, tendo como objetivo identificar os processos de implementação necessários à empresa estudada (BOTELHO; TRIGUEIRO; RICIERI, 2014). O método é definido como o caminho utilizado pelas pesquisas e varia a depender do tipo de objetivo que se pretende alcançar. É empregado em uma área do conhecimento e, a partir de um problema desta área, aponta-se onde o estudo almeja chegar e como o procedimento será efetuado (LIBÓRIO; TERRA, 2015). Este trabalho promove a reflexão diante da apuração de dados e de acordo com as

RC: 102385

Link de acesso:

https://www.nucleodoconhecimento.com.br/administracao/estrategias-demonitoramento 
informações obtidas. Apresenta-se o seu objetivo, as técnicas e estratégias para redução de perdas de materiais utilizados nas instalações, no caso desta proposta.

\subsubsection{QUANTO À NATUREZA}

O estudo tem por natureza a abordagem qualitativa, pois esta permite a coleta de dados e análise dessas informações em torno do que está sendo pesquisado, ou seja, estudado. Apresenta- se um conjunto de práticas associado aos estudos descritivos (GIL, 2017).

A natureza da pesquisa científica apresenta diferentes modos, cada um com suas características, de acordo com sua finalidade. A pesquisa foi definida como básica ou aplicada. Parte-se de um único método (KINCHESCKI, 2015).

A pesquisa neste projeto possui a finalidade de resolver os problemas encontrados na organização que foram selecionados por meio de controles para redução de perdas de materiais. Os dados foram coletados a partir de pesquisas de campo que detalharam e aprofundaram esses dados.

\subsubsection{QUANTO AOS FINS}

O objetivo é o de analisar os casos que possuem particularidades a serem verificadas (PEREIRA et al., 2018).

O objetivo é o de explorar informações acerca do assunto que foi abordado no âmbito da pesquisa de campo, determinando-se, nesse processo, os mecanismos necessários ao alcance dos objetivos e soluções para o problema de pesquisa (CORREA; COSTA, 2012).

A pesquisa promoveu a amplificação do conhecimento acerca dos fenômenos ocorridos na empresa estudada. Configura-se, também, como descritiva, pois

RC: 102385

Link de acesso:

https://www.nucleodoconhecimento.com.br/administracao/estrategias-demonitoramento 
identificou-se e retratou as características e problemas da organização, de acordo com as entrevistas feitas dentro da organização.

\subsubsection{QUANTO AOS MEIOS}

A pesquisa, quanto aos meios, fundamenta-se nos problemas que afetam a empresa estudada, considerando, para fins de análise, os recursos disponíveis. O embasamento teórico foi feito com base em livros e artigos publicados para melhor compreender o tema (KOCHE, 2015). A pesquisa de campo diz respeito às investigações e experiências vividas. O problema da pesquisa surge da coleta das das informações. Analisou-se oportunidades voltadas à criação de estratégias que permitem solucionar os problemas das organizações (MENEZES et al., 2017). projeto foi baseado em pesquisas de campo e nas entrevistas junto aos colaboradores internos e externos, utilizando-se da coleta de dados da organização para chegar-se à solução para o problema relacionado aos desperdícios dos materiais.

\subsection{CARACTERIZAÇÃO DA EMPRESA}

A INFORTREAD foi fundada em 2009 e hoje se tornou uma das maiores empresas do Amazonas no ramo da tecnologia e internet, aumentando a cada dia o número de clientes que procuram pelos seus serviços. Possui uma infraestrutura bemorganizada e está localizada na cidade de Manaus, onde armazena e processa todo o serviço oferecido. Conta com uma equipe de 23 colaboradores que se comprometem diariamente a fornecerem um serviço de qualidade aos clientes. Inicialmente projetada para atender as prefeituras do Estado, especializou-se, a longo prazo, no ramo voltado ao fornecimento de certos tipos de materiais a órgãos como Câmaras, SAAEs, IMTUs e outros órgãos municipais. Localizada em Manaus, a sede da INFORTREAD abarca as áreas administrativas e operacionais, assim como o setor de processamento e armazenamento de dados. $O$ acesso é permitido

RC: 102385

Link de acesso:

https://www.nucleodoconhecimento.com.br/administracao/estrategias-demonitoramento 
somente diante de identificação e autorização na portaria, sendo limitado ao serviço necessitado pelo cliente.

\section{RESULTADOS E DISCUSSÕES}

Com estudo feito na empresa INFORTREAD, observou-se, a partir da realização do diagnóstico na organização, algumas lacunas. Foi possível avaliar as áreas funcionais da organização e pôde-se identificar que a organização necessitava de melhorias nos processos organizacionais a fim de que pudesse se desenvolver em áreas diferentes, como nas áreas ligadas às operações e finanças, porém, identificou-se a área de Logística como aquela que registrou os piores indicadores de desempenho, como demonstra o gráfico a seguir:

Gráfico 01 - Média - Desempenho por área funcional

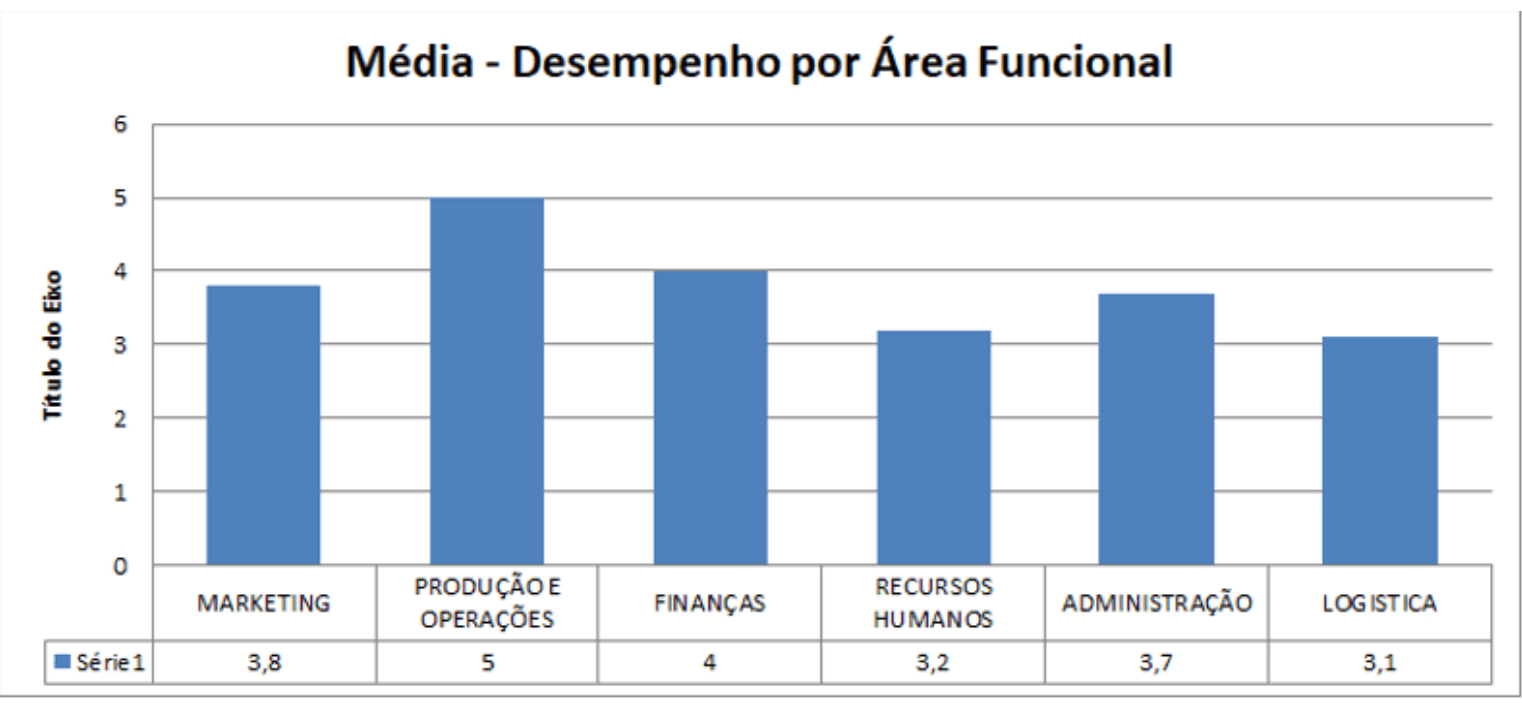

Fonte: Elaborado pelos autores, 2021

Observa-se que a organização possuía um bom desempenho na área de Produção e Operações e Finanças em relação às áreas médias, representadas pelo Marketing, Administração e Recursos Humanos, áreas essas que buscavam a melhoria em seus desempenhos. Nota-se no quadro 01, relacionado à área

RC: 102385

Link de acesso:

https://www.nucleodoconhecimento.com.br/administracao/estrategias-demonitoramento 
funcional da Logística, o quesito que apresentou maiores necessidades, o que demandou uma intervenção urgente.

Quadro 01 - Logística

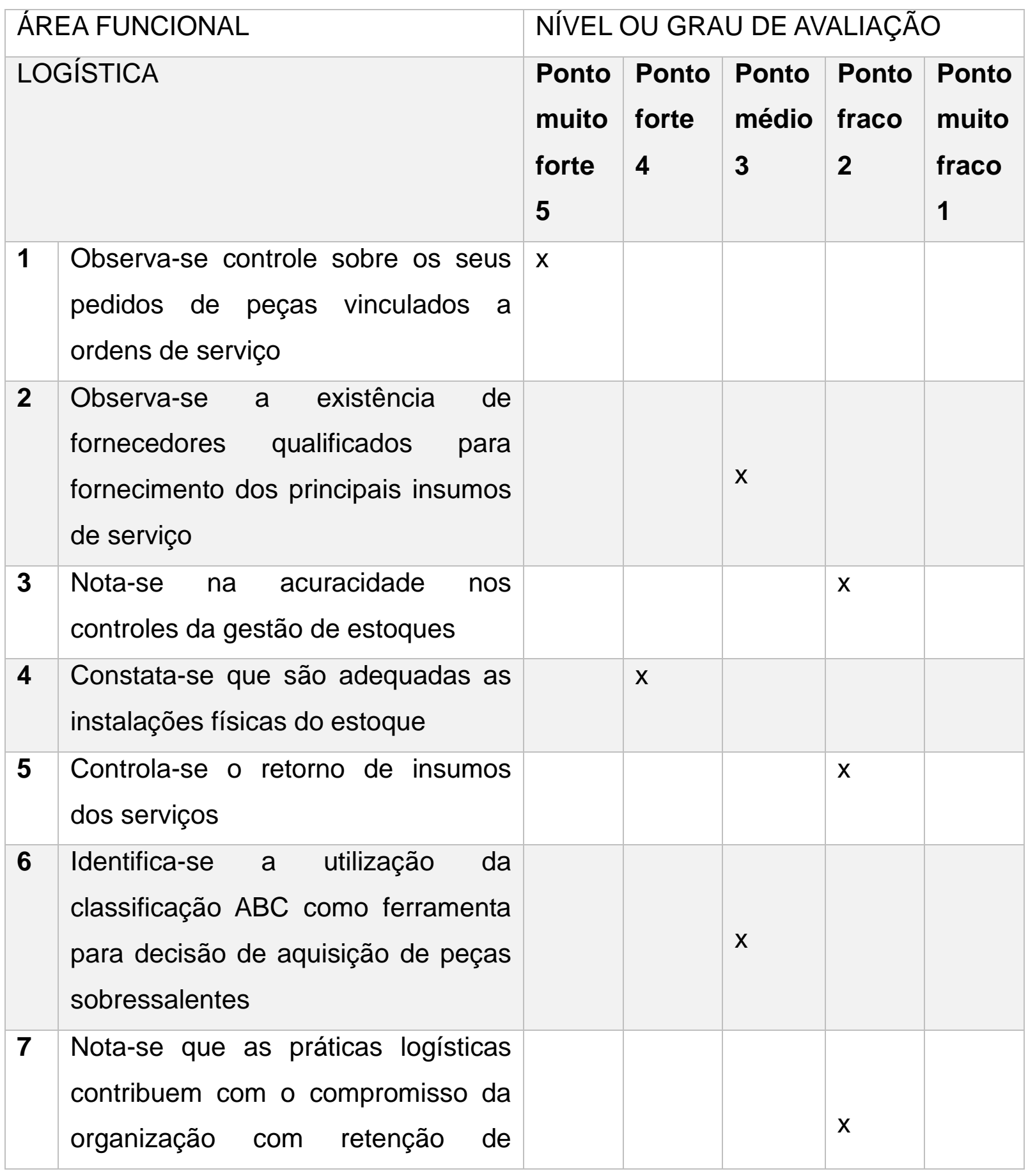

RC: 102385

Link de acesso:

https://www.nucleodoconhecimento.com.br/administracao/estrategias-demonitoramento 


\begin{tabular}{|c|c|c|c|c|c|c|}
\hline & clientes & & & & & \\
\hline 8 & $\begin{array}{l}\text { Controla-se trade-off dos custos } \\
\text { logísticos em relação aos serviços } \\
\text { prestados }\end{array}$ & & & & $X$ & \\
\hline 9 & $\begin{array}{l}\text { Analisa-se os custos de inventário } \\
\text { de peças sobressalentes }\end{array}$ & & $x$ & & & \\
\hline 10 & $\begin{array}{l}\text { Registra-se que dispõem de Frota } \\
\text { própria suficiente para atender a } \\
\text { demanda }\end{array}$ & & & & $X$ & \\
\hline \multicolumn{2}{|c|}{ TOTAL $(\Sigma)$} & 5 & 8 & 8 & 10 & 0 \\
\hline \multicolumn{2}{|r|}{ MÉDIA POR GRAU (POR COLUNA) } & 0,5 & 0,8 & 0,8 & 1 & 0 \\
\hline \multicolumn{2}{|c|}{ DESEMPENHO DA ÁREA } & \multicolumn{5}{|l|}{3,1} \\
\hline
\end{tabular}

Fonte: Elaborado pelos autores, 2021

Nota-se, ao analisar os quesitos diagnosticados, que os maiores problemas se relacionavam à falta de controle de insumos no decorrer da realização dos serviços, o que acabou gerando perdas e desvios de insumos. Sendo assim, este estudo de caso pretende responder ao seguinte problema de pesquisa: Como reduzir as perdas dos insumos nas instalações por meio de implementação e controle dos serviços?

\subsection{PLANEJAMENTO DE AÇÕES}

São as ações que promovem as mudanças necessárias que determinam o setor no qual se deve atuar. A estratégia permite alcançar os objetivos na organização de modo planejado. As metas devem ser mensuráveis e precisam contar com prazos determinados e capazes de serem cumpridos por todos os membros da organização. 
Quadro 02 - Ações interventivas

\begin{tabular}{|c|c|c|c|c|}
\hline & Ações Interventivas & Cronologia & Duração & Custo \\
\hline 01 & $\begin{array}{l}\text { Estruturar um } \\
\text { mapeamento completo do } \\
\text { processo }\end{array}$ & Agosto/2021 & 10 dias & $\mathrm{R} \$ 1.500,00$ \\
\hline 02 & $\begin{array}{lrr}\text { Criar } & \text { mapas } & \text { inteligentes } \\
\text { para } & \text { a } & \text { gerência } \\
\text { supervisionar } & \text { as } \\
\text { operações diárias } & \end{array}$ & Agosto/2021 & PERMANENTE & $\mathrm{R} \$ 1.200,00$ \\
\hline 03 & $\begin{array}{l}\text { Implantação do ciclo } \\
\text { PDCA }\end{array}$ & Agosto/2021 & PERMANENTE & $\mathrm{R} \$ 1.500,00$ \\
\hline 04 & $\begin{array}{l}\text { Implantação da Curva } \\
\text { ABC para reduzir a } \\
\text { aquisição de insumo } \\
\text { desnecessário. }\end{array}$ & Setembro/2021 & PERMANENTE & $\begin{array}{l}\mathrm{R} \$ \text { 350/HORA } \\
\mathrm{S} \text { DA MÃO DE } \\
\text { OBRA } \\
\text { INTERNA }\end{array}$ \\
\hline 05 & $\begin{array}{l}\text { Elaborar treinamento de } \\
\text { redução de custos voltado } \\
\text { para os técnicos de } \\
\text { instalações }\end{array}$ & Setembro/2021 & 15 dias & $R \$ 1.200,00$ \\
\hline 06 & $\begin{array}{l}\text { Criar um formulário de } \\
\text { controle para obter as } \\
\text { informações dos insumos } \\
\text { usados nas realizações } \\
\text { dos serviços }\end{array}$ & Setembro/2021 & PERMANENTE & $\begin{array}{l}\mathrm{R} \$ \text { 250/HORA } \\
\text { S DA MÃO DE } \\
\text { OBRA } \\
\text { INTERNA }\end{array}$ \\
\hline
\end{tabular}

Fonte: Elaborado pelos autores, 2021

As ações descritas tiveram como intuito a promoção dos mecanismos necessários à correção dos pontos fracos relacionados ao setor mais crítico, a área da Logística. $\mathrm{O}$ intuito foi solucionar os problemas desta área. Assim, obteve-se melhorias no setor

RC: 102385

Link de acesso:

https://www.nucleodoconhecimento.com.br/administracao/estrategias-demonitoramento 
com a inserção de ações efetivas e das respectivas implementações que, de fato, ajudaram no progresso da empresa, pois atenderam, após a implantação, às demandas diárias, com melhor proveito e qualidade na entrega dos serviços.

\subsubsection{ESTRUTURAR MAPEAMENTO COMPLETO DO PROCESSO.}

O mapeamento do processo é essencial à empresa. Demanda um acordo entre os colaboradores envolvidos para que entendam como o seu trabalho impacta no das demais pessoas. Objetiva uma maior transparência no processo, promovendo os conceitos de maneira mais clara para os colaboradores, pois busca melhorias dentro da empresa por meio da identificação de gargalos para solucioná-los e chegar às melhorias. O mapeamento de processos na organização é a ferramenta gerencial a ser executada para entender o desempenho das etapas do processo produtivo, de forma a melhorá-lo, por isso, os responsáveis devem saber como manusear o controle de todos os passos-chave relacionados ao funcionamento de empresa. Isso permite que a empresa melhore os processos já existentes ou, se for necessário, que implante novas estratégias, alterando a operação.

Quadro 03 - 5w2h - Estruturar mapeamento completo do processo
Estruturar mapeamento completo do processo
O que? Mapeamento do processo
Por quê? Para entender os pontos fortes e fracos dos problemas e necessidade de melhoria
Onde? Na empresa Infortread
Quando? Na primeira semana do mês de agosto de 2021
Quem? Departamento de Logística
Reunindo os colaboradores para definir como será estruturado e
Como ? aplicado o mapeamento do processo dentro da empresa para corrigir os gargalos e obter a 
melhoria.

Quanto? $\mathrm{R} \$ 1.500,00$

Fonte: Elaborado pelos autores, 2021

O processo de estruturação foi feito em cooperação com os colaboradores e, nesse processo, identificou-se os pontos fortes e fracos, tomando medidas corretivas onde foi necessário, criando, assim, um maior fluxo de trabalho, bem como despertou-se os avanços no processo como um todo. Portanto, a redução do desperdício de tempo e a maximização da produtividade foram duas das principais e mais perceptíveis mudanças provocadas pelo mapeamento e pelas correções nos processos diários da empresa.

\subsubsection{CRIAR MAPAS INTELIGENTES PARA A GERÊNCIA SUPERVISIONAR AS OPERAÇÕES DIÁRIAS}

O bom desenvolvimento do mapa inteligente na organização fomentou um melhor planejamento em toda a área das operações, fornecendo informações sobre as falhas que impediam a chegada às melhorias. Tais informações foram obtidas por meio dos processos e operações desempenhados no dia a dia organizacional. A medida em que se estudou a área organizacional, permitiu-se focar de uma melhor forma nos problemas que afetavam a empresa, estabelecendo, então, um planejamento de ações que foi desempenhado pelos responsáveis, cujo intuito era evitar grandes problemas que impactavam as operações diariamente, com vistas a manter um equilíbrio entre as operações para evitar qualquer tipo de impacto que pudesse prejudicar a organização diante dos seus clientes.

Quadro 04 - 5w2h - Criar mapas inteligentes para a gerência supervisionar as operações diárias

Criar mapas inteligentes para a gerência supervisionar as operações diárias

RC: 102385

Link de acesso:

https://www.nucleodoconhecimento.com.br/administracao/estrategias-de- 


\section{O que? Mapas inteligentes}

Por quê? Para verificar as falhas das operações em busca das melhorias

Onde? Na empresa Infortread

Quando? Na terceira semana do mês de agosto de 2021

Quem ? Departamento de Logística e operações

Mediante as disponibilidades dos supervisores das áreas, definido qual

Como ?

a forma mais adequada para se aplicar

Quanto? $R \$ 1.200,00$

Fonte: Elaborado pelos autores, 2021

A execução dos mapas inteligentes foi crucial para coleta de dados e informações essenciais para a organização. Teve-se como objetivo fazer com que esta estivesse precavida contra futuros problemas, dispensando tempo para analisar problemas internos e a situação do mercado atual. Os mapas foram aplicados de acordo com a realidade da empresa. Assim, houve uma evolução considerável na qualidade dos serviços prestados pela empresa, pois as prioridades estavam bem definidas, objetivos e metas eram realistas e houve a participação de toda equipe, pois esta trabalhou em conjunto com os supervisores das áreas correlatas.

\subsubsection{IMPLANTAÇÃO DO CICLO PDCA}

A importância do ciclo Pdca para empresa está ligada à redução de custo e dos desperdícios dos materiais nas instalações. É o método que permite o controle dentro dos processos da empresa, com objetivo de atingir as metas das da empresa e reduzir o uso indevido de materiais. É uma ferramenta que otimiza, diariamente, a prática gerencial. O ciclo PDCA visa, portanto, a melhor execução das estratégias recomendadas, nesse caso, à empresa INFORTREAD, fomentando-se, então, as melhorias contínuas em todos os processos, cujo intuito, nesta empresa, foi o de

RC: 102385

Link de acesso:

https://www.nucleodoconhecimento.com.br/administracao/estrategias-demonitoramento 
reduzir, de maneira significativa, as falhas principais, visando à medição do desempenho da gestão por meio do Ciclo PDCA.

Quadro 05 - 5w2h - Implantação do ciclo Pdca

\section{Implantação do ciclo PDCA}

O que? Ciclo PDCA

Por quê? para reduzir os desperdícios dos materiais nos serviços prestado

Onde? Na empresa Infortread

Quando? Na Quarta semana do mês de agosto de 2021

Quem? Departamento de Produção e Operação

Por meio da análise de novas regras e uma cultura mais controlada

Como? entre a empresa e os colaboradores

Quanto? $\mathrm{R} \$ 1.500,00$

Fonte: Elaborado pelos autores, 2021

Com o emprego da ferramenta, reduziu-se os custos e desperdícios. A aplicação do ciclo PDCA necessitou que fossem empregues ações que auxiliaram no alcance das metas estipuladas, para, em seguida, fossem analisados todos os resultados e, com isso, foram corrigidas as possíveis falhas. Foi realizado de forma exponencial na empresa em questão. Por fim, conduziu-se a um aprimoramento em suas operações, o que foi um ponto positivo para a organização, pois o ciclo PDCA trouxe bons resultados a curto e longo prazo, bem como propiciou a tomada de decisões mais racionais.

\subsubsection{IMPLANTAÇÃO DE CURVA ABC PARA REDUZIR A AQUISIÇÃO DE INSUMO DESNECESSÁRIO}

Em relação à implantação das melhorias para a empresa INFORTREAD, sugeriu-se a ferramenta Curva $A B C$, pois as suas funções permitiram diagnosticar as

RC: 102385

Link de acesso:

https://www.nucleodoconhecimento.com.br/administracao/estrategias-demonitoramento 
características demandadas na empresa para determinação dos itens de maior importância ou impacto. A ferramenta foi essencial ao processamento das informações da organização, bem como foi crucial para tomada de decisão. A Curva $A B C$ promoveu melhorias para organização, de modo que esta pudesse chegar aos resultados esperados. Foi fundamental que a empresa verificasse e atualizasse os seus inventários de acordo com a ferramenta Curva $A B C$.

Quadro 06 - 5w2h - Implantação de Curva ABC para reduzir a aquisição de insumo desnecessário

Implantação de Curva $A B C$ para reduzir a aquisição de insumo desnecessário

O que? Curva $A B C$

Por quê? Para evitar prejuízo tanto financeiro como nos produtos

Onde? Na empresa Infortread

Quando? Na primeira semana do mês de setembro de 2021

Quem? Departamento financeiro, logística e produção e operação

Através de treinamento e palestra voltada as atividades desenvolvidas dentro do setor

Como?

Quanto? R\$ 350/HORAS DA MÃO DE OBRA INTERNA

Fonte: Elaborado pelos autores, 2021

Para a execução da Curva $A B C$ com maior eficiência no estoque foi necessário um levantamento completo acerca dos itens disponíveis, para, em seguida, catalogá-los a partir de normas específicas, para, assim, criar um estoque mais próximo da realidade de vendas, reduzindo, consequentemente, o desperdício de insumos. Com isso, houve o aumento da lucratividade e melhor monitoramento da saúde financeira do negócio, sendo essas duas das vantagens fornecidas pelo bom manuseio da Curva $A B C$, que é muito utilizada em estoques, produzindo resultados eficazes, pois seu custo é baixo e de fácil aprendizado para os colaboradores do setor.

RC: 102385

Link de acesso:

https://www.nucleodoconhecimento.com.br/administracao/estrategias-demonitoramento 


\subsubsection{ELABORAR TREINAMENTO DE REDUÇÃO DE CUSTOS VOLTADO PARA OS TÉCNICOS DE INSTALAÇÕES}

O treinamento com vistas à redução de custo foi necessário para que todos os colaboradores e gestores pudessem conhecer cada procedimento, bem como todos os processos realizados, até que houvesse a finalização das instalações, com vistas a obter maior qualidade e eficiência, assim como melhores retornos. O conhecimento acerca dos custos da empresa foi de grande importância para o colaborador, pois este aprendeu como evitar desperdícios relacionados a insumos, para que pudesse, dessa forma, lucrar.

Quadro 07 - 5w2h - Elaborar treinamento de redução de custos voltado para os técnicos de instalações

Elaborar treinamento de redução de custos voltado para os técnicos de instalações O que? Treinamento

Por quê? Para que todos os colaboradores envolvidos na instalação saibam da importância dos custos nos serviços

Onde? Na empresa Infortread

Quando? Na segunda semana do mês de Setembro de 2021

Quem? Departamento financeiro, recursos humanos, logística e produção e operação

Através de treinamento com os gestores e colaboradores das áreas, de

Como? acordo com as suas atividades.

Quanto? $\mathrm{R} \$ 1.200,00$

Fonte: Elaborado pelos autores, 2021

A capacitação quanto ao manuseio de informações fundamentais foi crucial para que os colaboradores soubessem qual era a realidade da empresa e a sua missão e valores e, por esse motivo, de maneira contínua, coube, ao gestor, investir nos

RC: 102385

Link de acesso:

https://www.nucleodoconhecimento.com.br/administracao/estrategias-de- 
treinamentos dessa magnitude, sempre que identificava e achava imprescindível a realização, nesse momento específico, de um novo treinamento. Além dessa ação ter sido primordial até mesmo para que as pessoas ligadas ao nível estratégico compreendam como os processos têm sido desempenhados, foi primordial para que todos se mantivessem atentos e conscientes quanto às deficiências dos setores. $O$ treinamento, portanto, foi uma forma auxiliar e orientar os colaboradores para que agissem conforme as normas da empresa. Criou-se, com isso, mais uma forma de ação para reduzir os desperdícios na organização.

\subsubsection{CRIAR UM FORMULÁRIO DE CONTROLE PARA OBTER AS INFORMAÇÕES DOS INSUMOS USADOS NAS REALIZAÇÕES DOS SERVIÇOS}

A utilização de formulário para o controle é essencial à saída de materiais, até mesmo pela demanda de serviços ser alta. Identificou-se o formulário como meio de transmissão entre a empresa e o colaborador, de modo que os métodos foram selecionados de acordo com as solicitações de serviços, mantendo, nesse processo, o padrão de qualidade da empresa INFORTREAD, porém, sem deixar de focar na redução de custo, bem como na melhor estrutura para a administração do fluxo de insumos necessários aos serviços. A empresa INFORTREAD, com a criação do formulário, pôde adquirir um controle mais eficiente para as saídas de insumos e até mesmo da relação com o cliente, com vistas a manter uma padronização dentro da empresa para adquirir informações exatas.

Quadro 08: 5w2h - Criar um formulário de controle para obter as informações dos insumos usados nas realizações dos serviços

Criar um formulário de controle para obter as informações dos insumos usados na realização dos serviços

O que? Formulário

Por quê? Para obter o controle de saída de insumos nos serviços realizados

RC: 102385

Link de acesso:

https://www.nucleodoconhecimento.com.br/administracao/estrategias-de- 
Onde? Na empresa Infortread

Quando? Na Terceira do mês de Setembro de 2021

Quem ? Departamento de recursos humanos, logística e produção e operação. Através de palestra com todos os colaboradores, informando a

Como? importância da padronização do formulário.

Quanto? R\$250/HORAS DA MÃO DE OBRA INTERNA

Fonte: Elaborado pelos autores, 2021

A importância da padronização do processo por meio de formulários foi feita de forma integrada aos colaboradores, visando um controle maior. Em razão disso, foi elaborado pelos responsáveis considerando a voz da coletividade, pois são os colaboradores os responsáveis pela prestação de serviços da INFORTREAD, logo, devem contribuir com a criação do documento. Foram informados quanto à necessidade de reduzirem custos na empresa, com vistas a tirarem um melhor proveito das matérias-primas. Portanto, o formulário conseguiu apresentar um feedback aos gestores de forma exata acerca do que saía do estoque da empresa durante as operações, reduzindo não só o desperdício, como, também, foi uma forma de auxiliar a gestão a ter um controle mais aprimorado em relação ao estoque e logística.

\section{CONSIDERAÇÕES FINAIS}

Este artigo teve como objetivo estudar, avaliar e propor métodos de melhorias para o setor de Logística da empresa INFORTREAD, pois esta apresentou diversas ineficiências, sendo elas condizentes à área de Logística, a mais crítica. Do mesmo modo, foram apresentadas algumas propostas por meio de sugestões e implementações metodológicas amparadas em estudos científicos e até mesmo considerou-se os dados empíricos para que a mesma pudesse sempre buscar por melhorias e otimização de seus resultados. As limitações encontradas por este estudo estão atreladas aos embasamentos teóricos científicos, pois existem $\mathrm{RC}: 102385$

Link de acesso:

https://www.nucleodoconhecimento.com.br/administracao/estrategias-de$\underline{\text { monitoramento }}$ 
diversos meios para que, por meio deles, possa-se chegar a um resultado esperado, até mesmo pelo fato de que se tem um motivo para que se chegue nesse resultado, que é a pergunta problema, que se apresentou, neste artigo, como uma questãoproblema direcionada ao setor da Logística.

Quanto à pergunta problema: Como reduzir as perdas dos insumos nas instalações por meio de implementação e controle dos serviços, sendo esta a questão norteadora, foi respondida a partir da estruturação a proposta de implementação de estratégias de ações voltadas à melhoria na área de Logística. As ações estavam ligadas à necessidade estruturar um mapeamento completo do processo, com vistas a identificar oportunidades direcionadas à simplificação, bem como teve-se como objetivo a criação de mapas inteligentes para a gerência supervisionar as operações diárias, implantando o Ciclo PDCA para melhoria contínua e a Curva ABC para reduzir os danos relacionados à aquisição de insumos desnecessários, bem como permitiu a elaboração de um treinamento voltado à redução de custo para os técnicos de instalações, assim como criou um formulário de controle para obter as informações acerca dos insumos utilizados na prestação dos serviços.

Com todo esse processo sendo realizado, houve um melhor acompanhamento quanto à execução do acordo relacionados aos atributos necessários à concretização de tais ações, com o intuito de que haja melhorias na área de Logística, o que fez com que todo o processo priorizasse as melhorias contínuas por meio do Ciclo PDCA, pois essa ferramenta também foi primordial para fazer ajustes necessários em torno desse processo, assim como foi essencial a ferramenta que mensura a qualidade dos processos, conhecida como $5 \mathrm{~W} 2 \mathrm{H}$. Os propósitos foram atingidos em todo o desenvolvimento da proposta, pois obteve-se boa consistência quanto aos embasamentos voltados à resolução das problemáticas. As fundamentações teóricas permitiram a chegada aos resultados, pois a teoria foi aplicada na prática. Houve a redução dos insumos nas instalações no que tocava aos serviços realizados na INFORTREAD, mantendo a qualidade em todas as fases.

RC: 102385

Link de acesso:

https://www.nucleodoconhecimento.com.br/administracao/estrategias-de- 
Verificou-se, também, com este estudo, que as empresas de serviço que têm os mesmos problemas podem usufruir de tais subsídios para implementarem a proposta em seus próprios ambientes. Além disso, esta pesquisa serve como base para futuros trabalhos sobre o tema.

\section{REFERÊNCIAS}

BOND, M. T.; BUSSE, A.; PUSTILNICK, R. Qualidade Total: o que é e como alcançar. Curitiba: Intersaberes, 2012.

BIAGIO, L. A. Como administrar a produção. Barueri, SP: Manole, 2015.

MENEZES, A. H. N. et al. Metodologia científica: teoria e aplicação na educação à distância. Petrolina, PE: Universidade Federal do Vale do São Francisco, 2017.

CORREA, J. C. da. S.; COSTA, M. de. M. Metodologia da Pesquisa 1 e 2. Belém: IEPA, 2012.

FERREIRA, A.R. Gestão de Processos. Brasília: Enap, 2014.

FERNANDES, F. C. F. Planejamento e controle da produção: dos fundamentos ao essencial. $1^{\text {a }}$ ed. São Paulo: Atlas, 2017.

FERNANDES, K. dos. Fundamentos e processos. $1^{\text {a }}$ ed. Curitiba: IESDE Brasil, 2012.

GIL, A.C. Como elaborar projetos de pesquisa. 6르 ed. São Paulo: Atlas, 2017.

GIMENES, M. A. O papel da ferramenta curva ABC na gestão de estoque. 2018. Disponível em: https://www.inesul.edu.br/revista/arquivos/arqidvol_48_1488486934.pdf. Acesso em: 09 nov. 2021.

GOBBI, B.C. Manual de Monografia ESAB 2012. Vila Velha, ES: Escola Superior Aberta do Brasil, 2012.

RC: 102385

Link de acesso:

https://www.nucleodoconhecimento.com.br/administracao/estrategias-demonitoramento 
BRITO JUNIOR, I.; SPEJORIM, W. Gestão Estratégica de Armazenagem. Curitiba: Lesde, 2012.

MARSHALL JUNIOR, I. Gestão da qualidade e processos. Rio de Janeiro: Editora FGV, 2012.

KINCHESCKI, G. F.; ALVES, R.; FERNANDES T. R. T. Tipos de metodologias adotadas nas dissertações do programa de pós- graduação em administração universitária da Universidade federal de santa catarina, no período de 2012 a 2014. In: XV Colóquio Internacional de Gestão Universitária, 2015.

KOCHE J. Fundamentos de metodologia científica: teoria da ciência e iniciação à pesquisa. 34를 ed. Petrópolis, RJ: Vozes, 2015.

LIBÓRIO, D.; TERRA, L. Metodologia científica. São Paulo: Rede Internacional de Universidades Loureate, 2015.

MIGUEL, P.A.C. Metodologia de pesquisa para Engenharia de Produção e Gestão de Operações. Rio de Janeiro: Abepro, 2012.

MOTTA, M. J.; LUSVARGHI, G. C. Logística 4.0 desafios e oportunidades na gestão da cadeia de suprimentos moderna. In: $18^{\circ}$ Congresso Nacional de Iniciação Científica, 2018.

MULLER, C. J. Planejamento estratégico, indicadores e processos: uma integração necessária. São Paulo: Atlas, 2014.

PEREIRA, A. S. et al. Metodologia da pesquisa científica. Santa Maria: Universidade Federal de Santa Maria, UAB/NTE/UFSM, 2018.

BOtELHO, J. M.; TRIGUEIRO, R. de. M.; RICIERI, M. Metodologia Científica. Londrina: Editora e Distribuidora Educacional S.A, 2014.

RC: 102385

Link de acesso:

https://www.nucleodoconhecimento.com.br/administracao/estrategias-demonitoramento 
RAUEN, F. J. Roteiros de investigação científica. $2^{\underline{a}}$ ed. ver. Tubarão: Fábio José Rauen, 2018.

SILVA, L. C. da. Gestão e Melhoria de Processos - Conceitos, Técnicas e Ferramentas. Ebook Kindle. São Paulo: Brasport, 2015.

SUZANO. M. A. Administração da produção e operações com ênfase em logística. Rio de Janeiro: Interciência, 2013.

VERGARA, S. C. Projetos e Relatórios de Pesquisas em Administração. 16 ed. São Paulo: Atlas, 2016.

Enviado: Outubro, 2021.

Aprovado: Novembro, 2021. 